\title{
Endoscopic vacuum therapy in Boerhaave's syndrome with open-pore polyurethane foam and a new open-pore film drainage
}

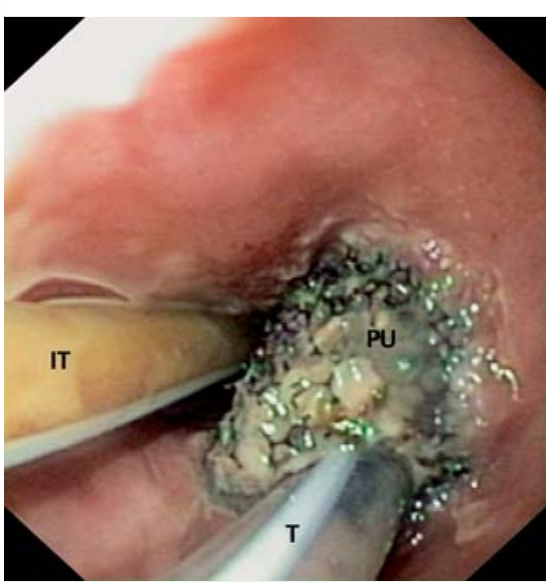

Fig. 1 Endoscopic view of intracavitary endoscopic vacuum therapy. PU, polyurethanefoam; T, drainage tube; IT, intestinal feeding tube.

The two main goals of treatment for esophageal leakages are closure of the defect and drainage of the septic focus. A few cases of successful endoscopic vacuum therapy (EVT) for Boerhaave's syndrome have been reported in studies of EVT in esophageal anastomotic leakages and perforations [1 - 4].

Intracavitary ( $\bullet$ Fig. 1 ) and intraluminal EVT with open-pore polyurethane foam drainage (OPD) has been described before in detail [5]. Application of vacuum results in closure of the defect and simultaneous internal drainage of the septic focus. The new open-pore film drainage (OFD) allows the diameter of the drainage tip to be minimized. The distal end of a drainage tube (Ventrol, $12 \mathrm{Fr} \times 120 \mathrm{~cm}$; Covidien Argyle, Dublin, Ireland) is wrapped in a very thin open-pore double-layered drainage film (Suprasorb CNP, Drainage Film; Lohmann \& Rauscher International GmbH \& Co.KG, Rengsdorf, Germany). The doublelayered drainage film is fixed around the tube with a suture ( $\bullet$ Fig. 2 ). The small diameter of the OFD device allows endoscopic placement through small openings. Thus, the tip of the OFD device is grasped with endoscopic forceps ( Fig.3) and pushed through the opening under endoscopic view.

In a 50-year-old man with Boerhaave's syndrome, a 4-cm-long distal esophageal rupture caused left-sided pleural empy-

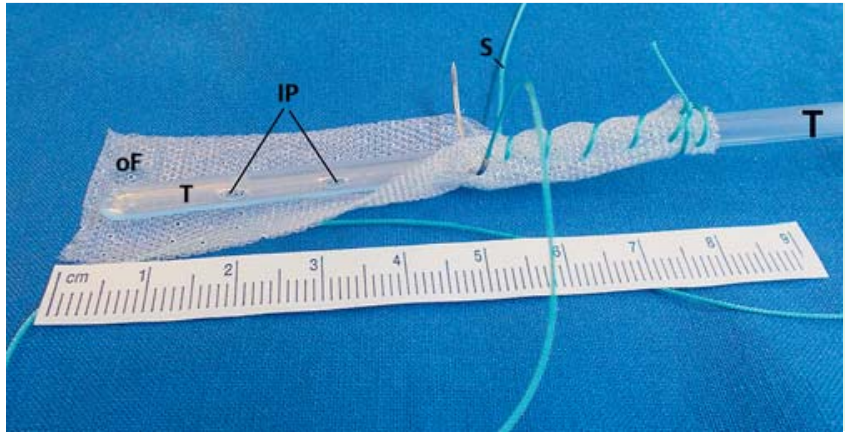

Fig. 2 Construction of the new open-pore film drainage. The distal end of a drainage tube $(\mathrm{T})$ with lateral perforations (IP) is wrapped in a very thin open-pore double-layered drainage film (oF), and is fixed with a suture $(\mathrm{S})$.

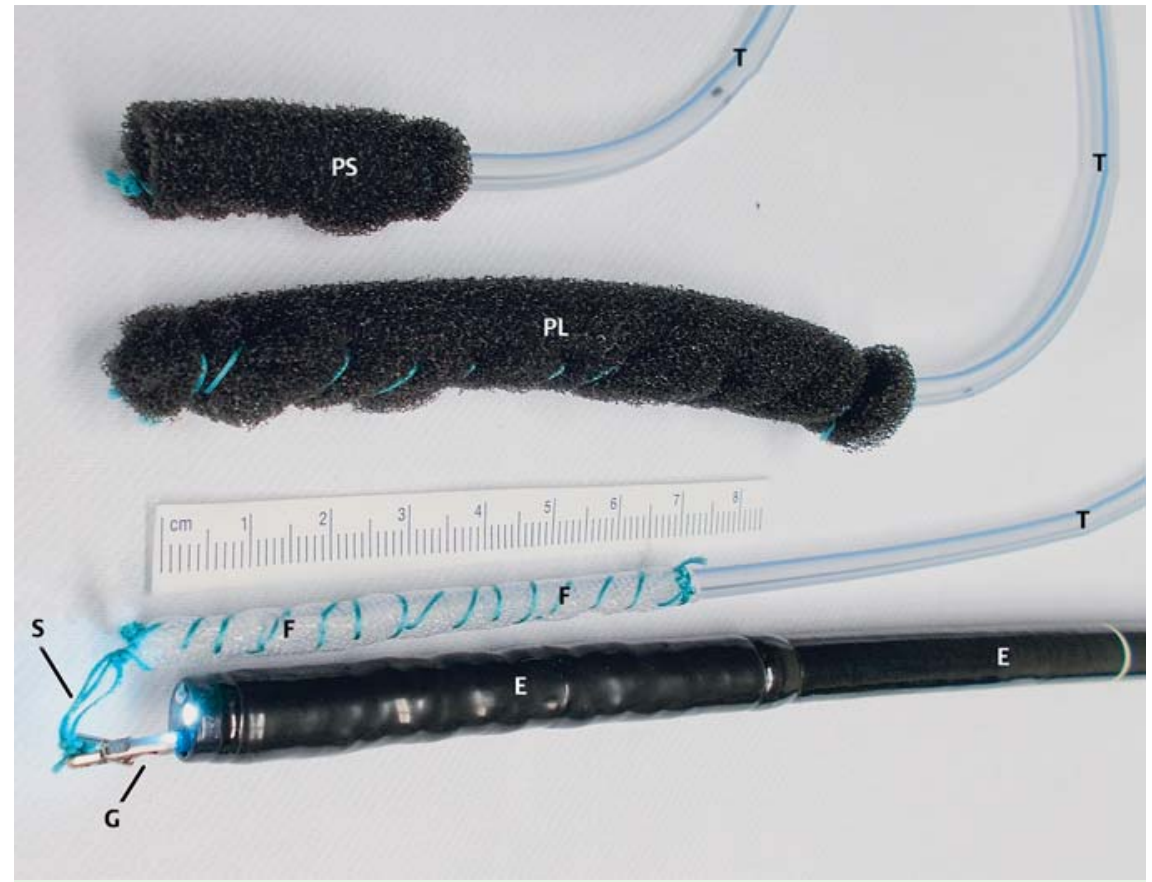

Fig. 3 Variants of the open-pore drainage devices used for endoscopic vacuum therapy (EVT). $\mathrm{T}, 12 \mathrm{Fr}$ drainage tube; PL, long polyurethane foam used for intraluminal EVT; PS, short polyurethane foam used for intracavitary EVT; E, endoscope. The suture $(S)$ at the distal end of the new open-pore film drainage device $(F)$ is grasped with endoscopic forceps $(G)$ for the placement procedure.

ema. Empyema was decorticated by open thoracotomy and drained using an external thoracic drain. The drain was removed 7 days postoperatively.

The esophageal perforation was treated solely with intraluminal and intracavitary EVT. After 20 days of EVT with an OPD, the perforation had shrunk to an 8-cm-long canal, $1 \mathrm{~cm}$ in diameter ( Fig.4). Placement of a new OPD was not possible because of the small opening of the canal. Therefore, the last period of treatment was performed using the new OFD. Endoscopic placement was easy, and the canal contracted to the size of the OFD (12 Fr) for one more treatment period of 3 days. EVT ended after a total of 23 days (ه Fig.5). At follow-up 30 days after the end of EVT, only a tiny scar was visible at the former site of perforation ( $\bullet$ Fig. 6 ).

\section{Endoscopy_UCTN_Code_CPL_1AH_2AG}

Competing interests: Dr. Loske is a consultant for Lohmann \& Rauscher. 


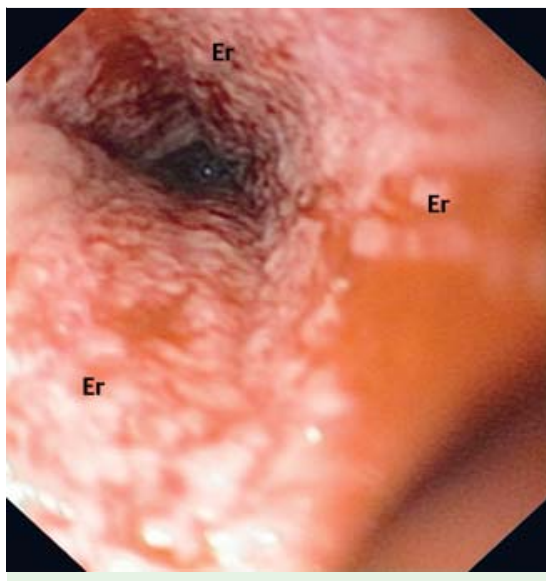

Fig. 4 Typical erosion pattern (Er) of the shrunken wound canal after removal of the intracavitary polyurethane foam drainage device after 20 days of endoscopic vacuum therapy.

\section{Gunnar Loske, Tobias Schorsch, Vera van Ackeren, Wolfgang Schulze, Christian T. Müller}

Department for General, Abdominal, Thoracic and Vascular Surgery, Katholisches Marienkrankenhaus Hamburg gGmbH, Hamburg, Germany

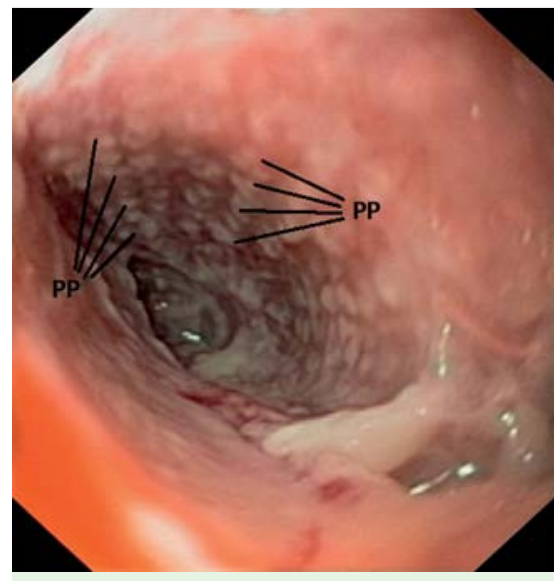

Fig. 5 Typical pimpled pattern (PP) after removal of the intracavitary open-pore film drainage tube following 23 days of endoscopic vacuum therapy.

\section{References}

1 Loske G, Schorsch T, Müller C. Endoscopic intracavitary vacuum therapy of Boerhaave's syndrome: a case report. Endoscopy 2010; 42 (Suppl. 02): E144-145

2 Loske G, Schorsch T, Muller C. Endoscopic vacuum sponge therapy for esophageal defects. Surg Endosc 2010; 24: 2531 - 2535

3 Kuehn F, Schiffmann L, Rau BM et al. Surgical endoscopic vacuum therapy for anastomotic leakage and perforation of the upper gastrointestinal tract. J Gastrointest Surg 2012; 16 : 2145-2150

4 Bludau M, Holscher AH, Herbold T et al. Management of upper intestinal leaks using an endoscopic vacuum-assisted closure system (E-VAC). Surg Endosc 2014; 28: 896-901

5 Loske G, Schorsch T, Müller CT. Intraluminal and intracavitary vacuum therapy for esophageal leakage: a new endoscopic minimally invasive approach. Endoscopy 2011; 43: $540-544$

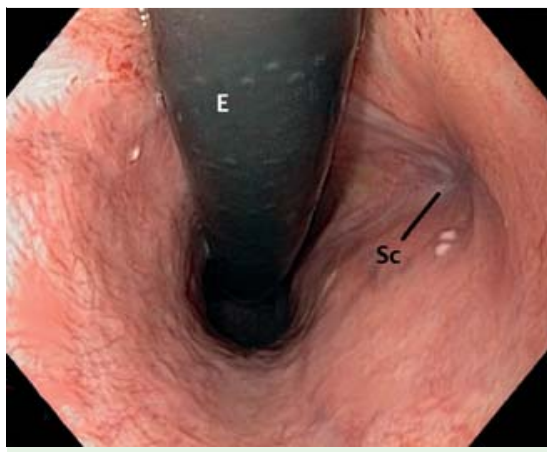

Fig. 6 Tiny scar (Sc) at the former site of perforation in the distal esophagus, 30 days after the end of endoscopic vacuum therapy. $E$, endoscope.

Bibliography

DOI http://dx.doi.org/

10.1055/s-0034-1392597

Endoscopy 2015; 47: E410-E411

(C) Georg Thieme Verlag KG

Stuttgart · New York

ISSN 0013-726X

\section{Corresponding author}

\section{Gunnar Loske, MD}

Department for General, Abdominal,

Thoracic and Vascular Surgery

Katholisches Marienkrankenhaus Hamburg $\mathrm{gGmbH}$

Alfredstrasse 9

22087 Hamburg

Germany

Fax: +49-40-25461400

loske.chir@marienkrankenhaus.org 